\title{
Lung Adenocarcinoma In Situ
}

National Cancer Institute

\section{Source}

National Cancer Institute. Lung Adenocarcinoma In Situ. NCI Thesaurus. Code C136486.

A localized non-invasive adenocarcinoma of the lung measuring $3 \mathrm{~cm}$ or less. It is characterized by a pure lepidic growth pattern and the lack of stromal, vascular, or pleural invasion. 